\title{
Health risk assessment of engine exhaust emissions within Australian ports: a case study of Port of Brisbane
}

\author{
Sanaz Jahangiri $\mathbb{1}^{\mathrm{a}}$, Natalia Nikolova $\mathbb{1}^{\mathrm{a}, \mathrm{b}}$, and Kiril Tenekedjiev $\mathbb{1}^{\mathrm{a}, \mathrm{b}}$

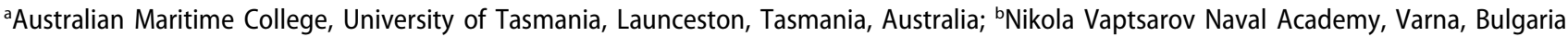

\begin{abstract}
Emissions from ocean-going vessels present a significant health risk to populations surrounding ports and damage the environment. Emissions from ships using heavy fuel oil include substantial amounts of sulphur dioxide, nitrogen oxides, and particulate matter. In order to assess the risk of these emissions, a complete methodology has been developed, based on the Australian Environmental Health Risk Assessment Framework. The method includes a detailed inventory of in-port and at-sea emissions using an activity-based approach applying downwash and near-field areas from first principles equations as well as the air-shed regions from CALPUFF dispersion modeling results for Port of Brisbane in 2013. The final risk values are validated against national and European guidelines. Various health impact assessments, as well as carcinogenic and ecological effects, are discussed in depth. This study offers a significant contribution to developing a baseline measurement of the current state of risk from emissions of the ocean-going vessels visiting the port, and suggests that, given the expected development of many Australian ports in the near future, the need for continual monitoring of shipping emissions is an essential and necessary area of research.
\end{abstract}

\section{ARTICLE HISTORY}

Received 31 August 2018

Accepted 26 December 2018

\section{KEYWORDS}

Emissions in ports; health impact assessment; risk assessment framework; risk values

\section{Introduction}

It is widely agreed that one of the most significant sources of air pollution is the emissions from shipping exhaust (Bailey and Solomon 2004; Colvile et al. 2001; Cooper 2003; Corbett and Koehler 2003; Eyring et al. 2005). Sulphur oxides, nitrogen oxides, and particulate matter are the most worrying and prominent emissions from diesel combustion. It is predicted that by 2020, based on current rates, worldwide $\mathrm{NO}_{\mathrm{x}}$ and $\mathrm{SO}_{\mathrm{x}}$ emissions will nearly double, and emissions from shipping will increase by two thirds compared to the available 2010 statistics (Eyring et al. 2010). Brisbane Port complies with international standards, and as a result, it relies on the International Maritime Organisation (IMO) through Annex VI of the International Convention for the Prevention of Pollution from Ships, the Maritime Pollution Convention (MARPOL) for the regulation of the ships' emissions on the Port's berth. Therefore, the regulations under Annex VI address the reduction in ships' emissions around the regions (Clarkson 2015). According to IMO (2014), the emissions are often dispersed, which hinders the possibility to trace their sources.

The emissions from in-ports are relatively small compared to the total shipping emissions, but they account significant health effects to the neighboring populations and have been linked to cardiopulmonary and cancer-related health problems (Clarkson 2015; Cooper 2003). Winebrake et al (2009), for example, estimated that $\mathrm{SO}_{\mathrm{x}}$ emissions from shipping during 2012 were implicated in approximately 87,000 deaths worldwide. Within the broader Australian coastal waters and within a specific time frame for a particular port (Jahangiri et al. 2018a), there are studies of the evaluation of the total ship emissions in Australia (Jahangiri et al. 2018b). However, no work has considered the distribution of emissions to quantify their risk to the local population (Goldsworthy and Goldsworthy 2015; Goldsworthy and Renilson 2013).

CONTACT Sanaz Jahangiri Sanaz.Jahangiri@utas.edu.au E Australian Maritime College, University of Tasmania, Launceston, Tasmania, 1 Maritime Way, Locked Bag 1397 Launceston 7250, Australia.

Color versions of one or more of the figures in the article can be found online at www.tandfonline.com/uevp. 
One of the biggest ports in Queensland and the third busiest port in Australia, Brisbane Port comprises seven container lodges in the harbor. Some of the major imports at this port include crude oil, fertilizers, chemicals, motor vehicles, gypsum and cement clinkers, paper and building products machinery while the exports include coal, refined petroleum products, grain and wood chips, sand minerals, scrap metal, tallows, live cattle, beef and dairy products, and wood. The Brisbane port which is busy during the whole year is also often visited by cruise ships and naval vessels, and with an active dredging program, the port handles more than 2600 ships and transports more than 28 million tons of cargo yearly. Before using the port, vessels must pick up a pilot outside the port waters at the Pilot Boarding Ground (PBG). Further, they cross the bay located at the Entrance Beacons (EB) near the mouth of the river, which is located approximately $83 \mathrm{~km}$ away from the PBG. From here, the ships are cleared to proceed to a berth which is 7-26 km away depending on the berth. The pilot must ensure that the vessels progress at a reduced speed. Similar to many ports, the Brisbane port borders include the entire transit from the PBG to the Fisherman Island and the Brisbane River berths. Moreover, as the Brisbane port is close to urban settlements, a high percentage of emissions arising from the ship, both in transit and at landing, affects the nearby residents. Because of the nature of economic activities taking place in major ports across the world, coastal areas around the world experience rapid and unplanned population growth, demographic change, and development. Indeed, there is the strong possibility that ports will develop as well as keep increase in shipping. Therefore, there is the need to identify reliable methods to quantify and estimate the risks of emissions.

This study presents a risk-based methodology for assessing ship emissions within the Port of Brisbane, based on the Australian Environmental Health Risk Assessment Framework. The role of this framework will be to provide a national approach to risk assessment of environmental health. The model is intended for use by environmental health agencies and regulatory bodies that evaluate the risk. The model is also designed to assist a broader audience seeking information on processes of ecological risk assessment in Australia. The methodology applied in this study will be demonstrated in a case study of oceangoing vessels within the Port of Brisbane boundaries during the calendar year 2013. There are three stages of the study: (1) creation of comprehensive inventory of vessel emissions, based on actual vessel movement data; (2) usage of that inventory to undertake atmospheric dispersion modeling as well as down-wash and near-field concentrations based on local meteorological and geographical conditions; and (3) assessment of each resulting emission concentration for its individual health impact, based on a calculated risk value for each concentration.

The nature of emissions taking place in the Port of Brisbane has necessitated the construction of a detailed emission inventory whose primary role is to quantify the emission rates of critical pollutants and the estimated fuel consumption and greenhouse gas emissions from ocean-going vessels in the port. However, the inventory did not comprise harbor crafts which consist of tugs and ferries. According to Jalkanen et al. (2009) and Lucialli et al. (2007), previous studies have indicated that the nature of emission from tugs and ferries are of minor importance as compared to ocean-going vessels (OGV). Data on the movement of ships are collected from records collected by the Port of Brisbane. In 2013, the data set included identifying the individual vessels, the types of ship, and the time the ship reached the pilot's boarding ground, the destination berth, and the corresponding departure time.

After the vessels arrive at the berth, they are assigned a separate operating mode. The time spent on the berth was provided in the original data set. The time taken for the pilots to dock and undock the vessel was included in the transiting time of the ship with berth arrival and departure time recorded as the time the last mooring lines were secured and released. In addition to the OGVs, the data set also included 30 yachts, 16 dredgers, and some barges and tugs (less than 100). However, the data did not represent the entire dredging and tug operations in the port because the dredging and tugging were infrequent. Default engine powers (both primary and auxiliary) and average service speeds of the vessels have 
been assigned from the various vessel types. Since there is no information about the fuel used by each ship, it was assumed that in all cases the ships used heavy fuel oil.

While conducting the review, it was assumed that all auxiliary engines were medium-speed diesel engines, and the review did not account for all vessels operating on gas turbines or in a nonconventional diesel-electric arrangement. Particularly, the assumptions could have resulted in significant differences because the Port of Brisbane mainly handles containerized cargo and bulk cargo. However, the assumptions could not necessarily hold for adaptation to a predominantly cruise or naval port. In such a case, emissions were calculated separately for the main and auxiliary engines. Jahangiri et al. (2018a) provides more information on the number of vessels, their categories, and the calculation of emissions.

The next step in the assessment entailed determining the actual concentrations received by human receptors in the adjacent areas based on the quantified emission releases within the port. For this purpose, the assessment used the atmospheric dispersion modeling to predict the level of concentrations of gaseous pollutants at ground level and similarly, the deposition of particulate matter. Various factors determine the selection of the dispersion model key including the source of pollutants. However, while there are several dispersion models, it is essential to select a suitable model to match the size and complexity of the domain. Many researchers (Bluett et al. 2004; Holmes 2006; NSW EPA 2005) agree that coastal atmospheric modeling is a challenge due to the complex weather conditions.

The nature of the of the coastline also hinders atmospheric modeling, and Bluett et al. (2004) question the ability of simpler Gaussian-plume models and suggest to use more advanced Lagrangian-based models. There exist sophisticated dispersion models to overcome the deficiencies of Gaussian plume steady-state models (Scire et al. 2000). For instance, the CALPUFF modeling system which can handle both complex terrain and meteorological conditions, making it suitable for coastal areas and areas with wind conditions. However, the drawback of the CALPUFF modeling system is the greater need for data input. The model domain selected for the assessment is a grid of 100 by $100 \mathrm{~km}$ with a grid space of $1 \mathrm{~km}$. The domain is centered at the Bureau of Meteorology (BoM), Brisbane Aero Monitoring Station, taking into account the coordinates for the domain corners.

CALPUFF modeling system requires that all coordinates are entered in the universal transverse Mercator format, and in this case, the modeling period is the full 2013 calendar year from January 1, 2013, 00:00 to January 1, 2014, 00:00. A land use category contour plot over the modeling domain is applied, land use data for Australia is taken from NOAA (2017). In conducting the assessment, the dataset covered the whole Australia, and it was possible to set the models at other locations in the country. The modeling domain's elevation data comes from the Shuttle Radar Topography Mission (USGS 2017). The model also includes a terrain elevation contour plot over the modeling domain. Australia's coastline data is from the Global SelfConsistent High-Resolution Geography Database (NOAA 2017). The dataset also included surface meteorological data from the BoM monitoring stations and precipitation and Upper Air data. There were also models of ten sources. Jahangiri et al. (2018a) provide further information on the wind rose plots and variances in the flow around the entire model.

\section{Application of a health risk assessment to Port of Brisbane}

\section{Health risk assessment}

Health risk assessment is the process of estimating the potential impact of a chemical, physical, microbiological, or psychosocial hazard on a given human population or ecological system, under a specific set of conditions and within a particular time frame (EnHealth 2012). The assessment follows strict common sense and can be applied to a whole series of rules or procedures (WHO Regional Office for Europe 2000). Figure 1 presents in detail the stages of risk assessment. 


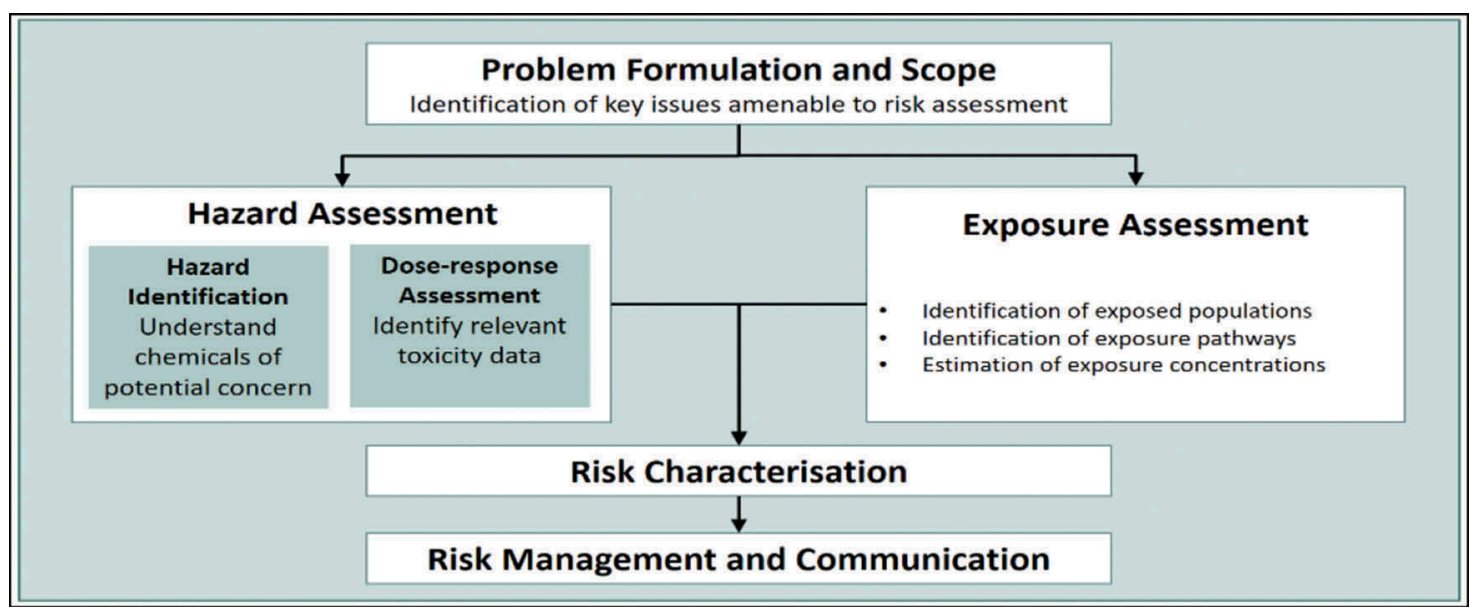

Figure 1. Stages of risk assessment.

The current risk assessment methods, however, do not allow actual estimates of low levels of exposure to environmental hazards, which means that emissions from international ships increasingly focus on proposed regulations in local, national, and international contexts (Bailey and Solomon 2004; California Environmental Protection Agency 2006; Cofala et al. 2007). However, regulatory deliberations have not been adequately informed since the extent of the health effects of shipping emissions has been unknown. Previous evaluations of regional shipping health impacts focused on European or Western United States regions and ignored short- and long-range Southern hemispheric pollutant transport (California Environmental Protection Agency 2006; Cofala et al. 2007), which undermined the global impact of shipping in local and regional jurisdictions and does not inform international policy-making correctly. Therefore, during the presentation of numerical calculations of risks, caution should be taken while assigning strict meaning to the numbers. The accuracy of differential risks estimates can be influenced by exposed population and variability in the environmental agents, inherent limitations in toxicological data, and the complexity of the exposure conditions. During quantification of some components such as exposure assessment and collection of data all uncertainties should be reflected in the risk assessment outcomes.

Following the above-explained approach, there are two types of risk assessment: qualitative and quantitative. Qualitative assessment (Figure 2) relies on professional judgment; it is simple, rapid, and can be very useful. The risk level can subsequently be explained either quantitatively or qualitatively (by categorizing risks into low, medium, and high). The approach utilized in AS/NZS ISO 31,000:2009 is the practical guidance on risk management (Standards Australia 2009).

This study, however, adopts a quantitative assessment to calculate risks, which does not rely heavily on judgment. This type of approach is more reliable as it takes into account the complexity of the process a lot more than it is possible with a qualitative approach (Department of the Environment 2016). The quantitative study approach used in the research involves computation of final risk value from the far and the near fields' concentrations, i.e., low levels of environmental hazards exposure for the case study of the Port of Brisbane. The perspective includes the Gaussian plumes and outcomes from CALPUFF dispersion modeling regarding the results from the health impact evaluation, short-term and long-term guideline validation assessment, ecological effects, and estimation of carcinogenic risks from the diesel particulate. CALPUFF is an advanced dispersion modeling used in estimating emissions of long-range transports from an area, point, lines, and volume sources. The sourcereceptor distances range from $50 \mathrm{~km}$ to several hundred kilometers. CALPUFF can produce hourly files on ambient concentrations for every 


\begin{tabular}{|c|c|c|c|c|c|}
\hline \multirow{2}{*}{$\begin{array}{l}\text { Probability } \\
\text { of Occurrence }\end{array}$} & \multicolumn{5}{|c|}{ Consequence of Occurrence } \\
\cline { 2 - 6 } & Very Low & Low & Moderate & High & Very High \\
\hline Very Low & & & & & \\
\hline Low & & & & & \\
\hline Moderate & & & & & \\
\hline High & & & & & \\
\hline Very High & & & & High Risk \\
\hline \multicolumn{2}{|c|}{ Low Risk } \\
\cline { 2 - 6 }
\end{tabular}

Figure 2. Example risk matrix.

species in the model including extinction coefficient and both dry and wet deposition fluxes. The extinction coefficient is associated with visible applications.

There are three tiers to quantitative risk assessment. Figure 3 is a schematic description of the particular elements that might comprise tiers I, II, or III. The tiered approach provides means for assessing an issue under consideration with an appropriate complexity level. Each tier supplies an equal degree of health protection. The level of uncertainty decreases with a growth in the number of assessment details, and the conceptual comprehension of the site condition is refined. As a result, the degree of caution that should be substituted for knowledge in the process of risk assessment is reduced.
(1) Tier I - it considers a particular amount of data and several guideline values. The assessment notes if the risk falls above or below the guideline. In some cases, circumstance requires an approach to be formed based on a specific issue or site due to the complexity and costs of contemporary environmental health risk. Tier 1, which is the most straightforward perspective, is supposed to be the first screening-type evaluation of vulnerability utilizing the conservative default exposure parameter estimate and comparing it to the published health guidelines. A prudent or conservative approach means assessing and managing the uncertainties inherent in a risk assessment that reduce the likelihood of harm.

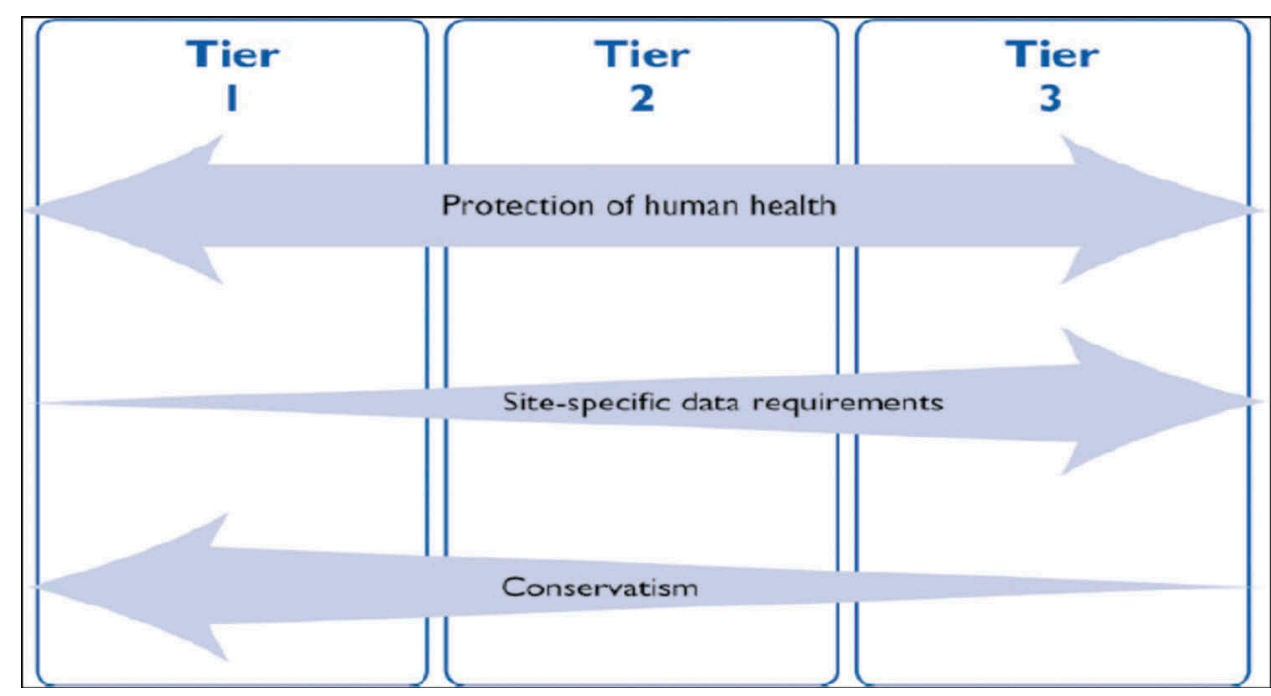

Figure 3. Elements of a tiered approach to a health risk assessment. 
(2) Tier II - it involves more modeling, extra data, and a deeper understanding of the situation and evaluates the risks involved. The approach works in terms of calculations and considers parameters and data sets.

(3) Tier III - it is significantly more complicated. Studies at this level may take years and can involve personal monitors when people observe their exposure to a hazard under investigation (EnHealth 2012). Tier III can include a much greater amount of detail and be probabilistic such as in Monte Carlo simulations. Tier III evaluations are rare, partly due to the tendency of any risk assessment to move gradually from Tier I but also because if Tier I indicates that risk is acceptable, then there is no point in moving to Tier II.

Tier II and III procedures require the collection of extra data on exposure and a detailed analysis and evaluation of data on dose response. These tiers involve computation of dosage on target tissues or translating dosages for animals to humans. Most jurisdictions uphold the tier approach of assessment for risks, but the correct usage and number of tiers varies.

A Tier II assessment is applied in this study, assuming that concentrations and ship stacks are port-wide and their final calculations are validated with available guidelines.

Exposure pathways are the processes that take a chemical or another agent into the environment from its release point to a situation in which a person becomes exposed. The routes of exposure are often reasonably obvious, but there may be some less obvious cases, such as the movement of contaminated groundwater or volatile chemicals from contaminated groundwater. The development of this process can be beneficial in identifying and quantifying the pathways of exposure (Figure 4).

The identification of concentrations and their risk to the population around the Port of Brisbane were carried out with regard to existing sensitive receptors. In formulating the scope of the problem, the chemicals to focus on and their sources, the pathway that connects the sources and receptors in a risk scenario for engine exhaust shipping emissions (air emissions) is inhalation.

\section{Summary of the approach for the study}

The ship and its environment are the main areas of focus for risk assessment. For a case study of the Port of Brisbane, an impact assessment on local air quality due to at-berth, maneuvring, and cruise ship emissions is presented. Air quality impact assessment has been carried out on different emission scenarios designed to produce long-term (i.e., annual average) and short-term (i.e., daily and hourly average) expected concentration levels to be compared to current air quality limits in the study area. Moreover, it is useful to divide the risk assessment component of the study into three sections, given that the CALPUFF model would not be the best model with time-changing

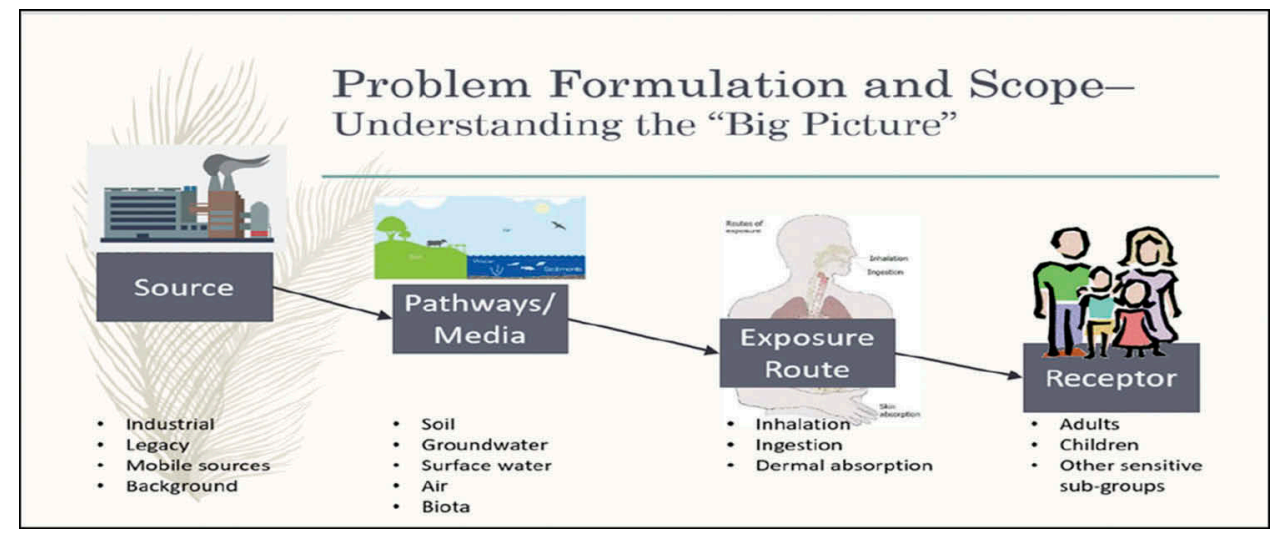

Figure 4. The principle of source-pathway-receptor. 
emissions regarding the time pattern of near-and near-field vessel traffic:

- Downwash: An area that may be affected on the ship itself (or on nearby ships). Calculations derived from first principle equations were applied to the average 1-hr and 24-hr levels of PM. Of interest in this case was the maximum concentration that someone on a ship could be exposed to.

- Near-field: Potential impacts to receptors on the port area. Gaussian plume modeling from first principles equations, averaging times of $1 \mathrm{hr}$ or $24 \mathrm{hr}$ for PM, were applied to calculate these concentrations.

- Airshed impacts: The modeling domain chosen for the model is a $100 \mathrm{~km} \times 100 \mathrm{~km}$ grid with $1 \mathrm{~km}$ grid spacing. The domain is centered at the Bureau of Meteorology, Brisbane Aero monitoring station. Potential impacts to the entire airshed, with pollutant concentrations assessed via CALPUFF dispersion modeling, using all averaging times as required. Receptors in this case were the following.

- The single worst affected location anywhere in the airshed. For this location, a comparison against available guidelines, and an assessment of carcinogenic risk from diesel particulate, were completed. Other sensitive receptors of interest, such as schools, kindergartens, hospitals, retirement homes, were chosen, and data from CALPUFF dispersion modeling were extracted for those locations. Assessment of risks at these locations was as per the single worst case location, as described above.

- The average location across the impacted airshed was detected and average concentrations across the airshed for the appropriate averaging times were calculated. Concentration-response functions (CRF)s derived from a study of the literature were used to calculate relevant health incidence rates.

- Assessment of carcinogenic risks from diesel particulate as well as in-depth toxicology reviews and ecological effects of concentrations were also completed.

\section{Results and discussion}

\section{Building downwash algorithm}

The downwash computations are obtained from the first principle equation presented by Briggs (1974). The primary objective of the section is to describe the state of the research on downwash phenomena of emissions as pollutants. The accounting for the downwash of pollutant dispersion is crucial since it can lead to curbing of dangerous circumstances by determining in advance the configurations of the stacks, buildings, and effluents. The concentration of effluents is a region that can lead to harmful effects on the environment. The most recent studies regarding stacks and structures are presented in this study. The models used are appropriately established and applied in the regulation of air pollution codes. This procedure of downwash correction is also still utilized in the regulation of plume rise models. It is recommended that 1-hr averages are used when possible (or $24 \mathrm{hr}$ of PM) to assess the risk. In this case, our focus is on the maximum concentration of the emissions under consideration that might affect a person on a ship. Building a downwash algorithm requires a cross-sectional area to be chosen and its dimensions combined with the velocity assumption that the mass emission rate from the chimney equals the one from downwash carry, which works on the principle of the conservation of mass. The final stage consists of choosing the downwash area and velocity to which to apply the algorithm.

The stack outlet area should be perpendicular to the direction of travel. If it is within a certain distance of the chimney, and if the ship is within the wake region, we assume that a certain percentage of concentrations is dragged into the wake. This assumption gives the rules for choosing the area and velocity. In theory, if there is a very high chimney (more than 2.5 times the height of surrounding buildings in the port area), concentrations will not decline. Similarly, if the plume rises very quickly, then nothing will be reduced. A plume may increase quickly if it has a higher velocity than a low wind, or if there is high momentum associated with temperature. 
A reasonable assumption is that there is an area equal to the cavity area and that the plume area equals the cavity area. This leads to assuming a $100 \%$ downwash option, which has been considered in this study. The dimension of the cavity is called the "cross stream width" which it is roughly the width of the building and the height of the cavity which is taken around a factor of three: three $\times$ two or three $\times$ the building height. The specific empirical values depend on the shape of the building, which in this study is the area that the crew occupies on the ship.

The cavity and stack tip are the two types of downwash procedures to be considered while conducting risk assessment. Cavity modules calculate the portion of plume mass obtained by and recirculated in the closer wake. The above method has not been used in the study because no crew could have been noticed in this area. The downwash velocity takes place when the speeds of the stacks are divided by the average velocities of free streams (Briggs 1974), which has also been implemented in our study (Table 1).

No stack tip downwash occurred during the time of this study because of the high stack outlet velocity and low reference wind speed (Table 1), which means that people on the ship were not affected by either kind of downwash.

There is, however, another way that a crew may be affected. Depending on the rate of plume rise, the cavity may extend or intercept the plume. A portion of that plume will then be downwashed into the cavity area and envelop the depth of the ship so that it covers the cavity of the vessel and not just the stack tip. This will be deflected around the ship, however, at some point, a separation occurs, and, instead of

Table 1. Stack tip downwash calculations.

\begin{tabular}{lll}
\hline Parameters & Units & \multicolumn{1}{c}{ Description/Comments } \\
\hline $\mathrm{V}_{\mathrm{o}}$ & $25 \mathrm{~m} /$ & Stack Outlet Velocity \\
& $\mathrm{s}$ & \\
$\mathrm{H}_{\mathrm{s}}$ & $20 \mathrm{~m}$ & Stack Outlet Height relative to Sea Level \\
$\mathrm{D}_{\mathrm{o}}$ & $0.8 \mathrm{~m}$ & Stack Outlet Diameter \\
$\mathrm{U}$ & $2 \mathrm{~m} / \mathrm{s}$ & Reference Wind Speed \\
$\mathrm{V}_{\mathrm{o}} / \mathrm{U}$ & 12.5 & If $\mathrm{V}_{\mathrm{o}} / \mathrm{U}<1.5$ Stack Tip Downwash Applies. \\
$\mathrm{H}_{\mathrm{s}}^{\prime}$ & $20 \mathrm{~m}$ & $\begin{array}{l}\text { If Stack Tip Downwash Applies: } \mathrm{H}_{\mathrm{s}}+2 \times \mathrm{D}_{\mathrm{o}} \times \\
\end{array}$ \\
& & $\left(\left(\mathrm{V}_{\mathrm{o}} / \mathrm{U}\right)-1.5\right)$ \\
& If Not: $\mathrm{H}_{\mathrm{s}}$ \\
\hline
\end{tabular}

following the contour of the vessel, the flow separates, and an eddy develops that may affect people aboard. As ships are designed to have velocities high enough to counter this, the enhanced turbulence effect is ignored in this study, which assumes the stacks are above the wake region. The effect is part of the screening assessment level, but it is a conservative, high estimation, and its application to ships differs from buildings due to their different geometrical shapes. The nature of a vessel is that it is streamlined to flow through the water, and the average wind speed in the cavity by definition is less in the downwash zone, resulting in a softer effect. The eddy, downwashed cavity will result in a lower concentration effect that may be better investigated in the near-field and air-shed area scenarios (also discussed in sections Gaussian plume modeling and CALPUFF dispersion modeling). Such outcome occurs because in the case of the eddy it is not the concentrated plume that matters but a mixture of the plume and the entire wake. In our scenario, we can ignore the number as it is very small.

\section{Gaussian plume modeling}

One of the most valuable tools in the estimation of atmospheric transport emissions in risk assessment is the Gaussian plume model (Amoatey et al. 2017; Khaniabadi et al. 2018; Zhang et al. 2000). The wind makes the dispersion of airborne concentration extremely complicated due to its variability in velocity. Additionally, the terrain of the land on the earth surface complicates the issue even further. Thus, there is no complete general equation expressing the physical association between the causative meteorological factors and processes in ambient concentrations of air pollution. The Gaussian plume model is the most widely used model for air pollution dispersion. Therefore, the distribution of the near-field plume is assumed to conform to a Gaussian distribution. The expression is then a function of the height of the stack, buoyancy, and emission velocity, which describes the shape of the plume in the nearest port areas. This study is a screening-level assessment, which assists in finding concentrations and their risk values as well as assessing them and 
analyzing how different variables may influence outcomes. The evaluation is done by selecting particular locations and heights at which to intersect the pure plume, provide the calculations for the concentrations under study, which may dilute in a certain amount of air, and analyze their effect on people living in the port.

The four input variables for a Gaussian distribution are emission rate, velocity, and temperature as well as wind speed. Other inputs such as the surface roughness are ignored as this study does not consider emissions being spread over the countryside; it is looking at relative changes such as how variance affects the final risk values. For a Gaussian distribution, there is no highly turbulent atmosphere, and neutral and stable atmospheric conditions are assumed in a generalized model.

Under neutral conditions, the plume rise equations are a function of the buoyancy and the exit velocity (Briggs 1974) (Table 2). This includes both a stable plume that is pure and an unstable one that is meandering. The stable plume continues to be the same size and retains high concentration until it reaches instability and then mixes vertically. Meandering plumes mix horizontally. Where the spread in the vertical direction and the horizontal direction of the test plume smoke is neutral, there is no change in height or temperature. Different stabilities, then, explain variable particulars. For example, D neutral means that it is adiabatic which in atmospheric terms means there is no energy exchange between the various heights.

Comparing the results with the final values in guidelines (Table 3 ), only ground level concentrations $(Z=0)$ in the first row exceed the final risk values (see supplemental data), indicating severe human exposure to ambient PM in the most developed and populated areas in Port of Brisbane. The guideline values account for the elevation of the source above the ground surface. The emission of pollutants and the atmospheric dynamics, which failed to distribute pollutants to the upper spheres of the atmospheric air and to other regions, explain why the ground level concentrations in this study exceed the recommended safety limits. The uncontrolled level of urbanization in terms of the emissions from urban sites together with emissions from automobiles, industries, and the combustion of solid wastes explains the level of pollutants in the atmosphere. The pollutants that are emitted remain concentrated and localized at ground level, because the stable atmosphere hinders their flow either vertically or horizontally. Low wind speeds, often below $5 \mathrm{~km} / \mathrm{hr}$ during the time of this study, and high levels of humidity, limited the diffusion of pollutants from a source region to other areas, as well as from the ground level upwards. Near-field studies consider the potential effects of pollutants on people on-shore, and employs the methods used in Gaussian plume modeling. As explained, except for ground-level concentrations, the maximum predicted concentrations appear reasonable and their comparison with the proposed screening model predictions show excellent agreement with the recommended risk values. In these near-field assessments, emissions forecasts take into consideration the mass of emissions and the duration and period of their release. Applying onsite turbulent velocity and wind as input returns estimated enough measurements of concentrations. This study collected data on emission patterns created in the vicinity of the source, and the results indicate that traditional models of dispersion, primarily utilized for regulation purposes, occasionally overestimate concentrations in the near field but underestimate the lower ranges of pollutant concentrations. Studies also indicate that the PRIME algorithm, utilized to compute dispersions in the wake cavities, overestimates pollutant concentrations in the near field and neglects upwind meandering (Isakov et al. 2004). Some studies offer an algorithm available in CALPUFF, a new model for regulating dispersion, which might calculate concentrations with high precision by accounting for upwind meandering near a source (Barclay and Borissova 2013). However, CALPUFF cannot offer reliable near-field concentration measurements from sources responsible for modern emissions if plume spreads are measured using estimates of turbulent velocities near to sources (Carotenuto et al. 2018). This study, designed to formulate a refined modeling perspective for near 
Table 2. Gaussian dispersion and plume rise calculations and risk values.

\begin{tabular}{|c|c|c|}
\hline Parameters & Units & Description/Comments \\
\hline Q & 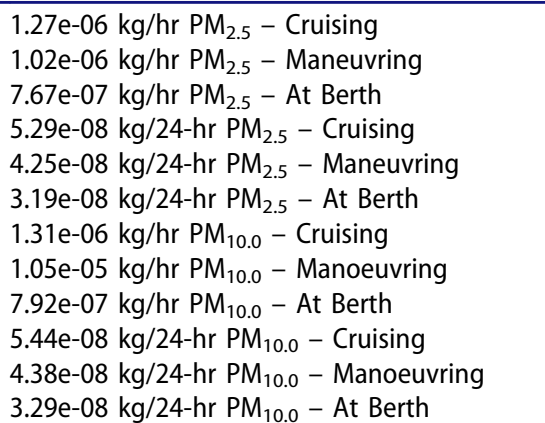 & Mass Emission Rate of Particulate Matter \\
\hline G & $9.81 \mathrm{~g} / \mathrm{ms}^{2}$ & Gravity Acceleration \\
\hline $\mathrm{T}_{\mathrm{a}}$ & $298 \mathrm{~K}$ & Ambient Temperature \\
\hline $\mathrm{U}$ & $2 \mathrm{~m} / \mathrm{s}$ & Reference Wind Speed \\
\hline$T_{0}$ & $539 \mathrm{~K}$ & Stack Outlet Temperature \\
\hline $\mathrm{R}_{\mathrm{o}}$ & $0.4 \mathrm{~m}$ & Stack Outlet Radius \\
\hline $\mathrm{V}_{\mathrm{oz}}$ & $25 \mathrm{~m} / \mathrm{s}$ & Stack Outlet Velocity \\
\hline$X$ & $100 \mathrm{~m}$ & Receptor Downwind Distance from the Stack \\
\hline Y & $0 \mathrm{~m}$ & Receptor Transverse Distance Relative to the Plume* \\
\hline $\mathrm{H}_{\mathrm{s}}^{\prime}$ & $20 \mathrm{~m}$ & Adjusted Stack Outlet Height Relative to Sea Level \\
\hline $\mathrm{H}_{\mathrm{s}}$ & $20 \mathrm{~m}$ & Stack Outlet Height Relative to Sea Level \\
\hline A & $0.50 \mathrm{~m}^{2}=n \times \mathrm{Ro}^{2}$ & Stack Cross-section Area \\
\hline $\mathrm{F}_{\mathrm{o}}$ & $\left.31.73 \mathrm{~m}^{4} / \mathrm{s}^{3}=(\mathrm{G} / \mathrm{Ta}) \times\left(\mathrm{T}_{\mathrm{o}}-\mathrm{T}_{\mathrm{a}}\right) \times \mathrm{V}_{\mathrm{oz}} \times \mathrm{Ro}^{2}\right)$ & Buoyancy Flux \\
\hline$\sigma_{y}$ & $\begin{array}{l}26.43 \mathrm{~m} \text { if Class A } \\
18.89 \mathrm{~m} \text { if Class B } \\
11.62 \mathrm{~m} \text { if Class D } \\
8.15 \mathrm{~m} \text { if Class } \mathrm{F}\end{array}$ & Standard Deviation of the Plume Distribution (y direction) (see supplemental data) \\
\hline$\sigma_{\mathrm{z}}$ & $\begin{array}{l}26.43 \mathrm{~m} \text { if Class } A \\
17.32 \mathrm{~m} \text { if Class B } \\
7.99 \mathrm{~m} \text { if Class } \mathrm{D} \\
1.58 \mathrm{~m} \text { if Class } \mathrm{F}\end{array}$ & Standard Deviation of the Plume Distribution ( $z$ direction) (see supplemental data) \\
\hline $\mathrm{H}$ & $74.57 \mathrm{~m}=\mathrm{H}_{\mathrm{s}}^{\prime}+\left(1.6 \times\left((\mathrm{Fo} \times \mathrm{X})^{2}\right)^{1 / 3}\right) / \mathrm{U}$ & Plume Total Centreline Height Relative to Sea Level \\
\hline$z^{\prime}$ & $\begin{array}{l}54.57 \mathrm{~m} \text { if PG: } A, B \text { and } D \\
6.05 \mathrm{~m} \text { if PG: } F\end{array}$ & Plume Rise Relative to Stack Outlet Height (see supplemental data) \\
\hline Z & $0-78 \mathrm{~m}$ & Receptor Vertical Distance above Sea Level \\
\hline$C(x, y, z)$ & See supplemental data & Local Concentration of the Pollutant at the Receptor \\
\hline
\end{tabular}

* The plume goes straight to the receptor, therefore it is zero

Table 3. Final risk guideline values.

\begin{tabular}{llcc}
\hline Pollutant & Averaging time & NEPM $\left(\mu \mathrm{g} / \mathrm{m}^{3}\right)$ & WHO $\left(\mu \mathrm{g} / \mathrm{m}^{3}\right)$ \\
\hline $\mathrm{PM}_{10}$ & $24 \mathrm{hr}$ & 50 & 50 \\
$\mathrm{PM}_{10}$ & $1 \mathrm{hr}$ & 2.08 & 2.08 \\
$\mathrm{PM}_{2.5}$ & $24 \mathrm{hr}$ & 25 & 25 \\
$\mathrm{PM}_{2.5}$ & $1 \mathrm{hr}$ & 1.4 & 1.4 \\
\hline
\end{tabular}

field application for regulation, used a case study approach, and the evaluation of its result showed a corresponding agreement with the literature.

\section{CALPUFF dispersion modeling}

\section{Health impact risk assessment}

The Health Impact Assessment is an international tool used to assess complex hazards and risks of exposure in particular areas. A comparison of risks to residents living near different ports illustrates how this study's risk assessment supports the aims of the Assessment, important components of which are to identify where and when public health is most likely to be endangered, and to recommend ways to reduce or eliminate the threat (Collins 2009). Short-term (daily) and longterm (annual) exposure to concentrations have been associated with increased daily and yearly health outcomes. The shape of the concentration-response relationship-particularly if there is a threshold-is critical for estimating public health impacts (Atkinson et al. 2012). This study investigated the concentration-response relationship between daily and yearly concentrations and their health impacts in Port of Brisbane for the calendar year 2013. Analysis of results showed the following (see supplemental data): 
- For the Port of Brisbane, long-term health end-points of $\mathrm{PM}_{2.5}$ were projected to annually cause $0.39 \%$ of the adult population to suffer cardiopulmonary effects, $0.42 \%$ of the population to exhibit Ischaemic heart disease, and $0.39 \%$ to be affected by lung cancer. In addition, the life expectancy lost projection was $0.002 \%$. The long-term effect of $\mathrm{PM}_{2.5}$ exposure also was projected to cause a $0.36 \%$ mortality rate in infants $(<12$ months of age).

- Short-term health end-points of $\mathrm{PM}_{2.5}$ daily affected $2.8 \%$ of adults with non-trauma diseases and $4.7 \%$ with cardiovascular diseases. In addition, $0.8 \%$ hospitalized due to this cardiovascular diseases, $2.2 \%$ due to cardiac failure as well as $1.0 \%$ for Ischaemic heart diseases. The daily concentrations also affected $1.69 \%$ with Myocardial infarction. In addition, $0.9 \%$ had to visit emergency departments for non-fatal heart attacks, $1.28 \%$ for Minor restricted activity days and $1.24 \%$ due to some work lost days due to being affected. Also, 1.19\% of 8-12-year old children suffered from acute bronchitis and $1.058 \%$ from lower respiratory symptoms.

- $\mathrm{PM}_{10.0}$ affected $1.18 \%$ of the population from all-cause mortality due to its long-term health endpoints annually as well as $16.4 \%$ affected from some years of lost life expectancy. This also caused $1.2 \%$ of the Infants $(<12$ months of age) with mortality. Also, $0.6 \%$ of population suffered from airway inflammation.

- $\mathrm{PM}_{10.0}$ short-term health endpoints were projected to cause $0.7 \%$ of the population to be subjected to cardiac hospitalization and 2.3\% to experience cardiac failure, $0.6 \%$ to suffer from pneumonia and acute bronchitis. In addition, $4.6 \%$ were projected to visit emergency departments for asthma and 25.8\% were affected by shortness of breath.

- The projected results for $\mathrm{NO}_{\mathrm{x}}$ long-term health endpoints are that $0.76 \%$ would experience asthma and $2.66 \%$ would experience airway inflammation annually. For NOx short-term health endpoints, the projected results are greater, with $1.49 \%$ experiencing non-trauma mortality, $1.40 \%$ experiencing cardiovascular issues, and
$3.43 \%$ experiencing respiratory issues. In addition, $0.8 \%$ of 15-64-year-olds and $0.02 \%$ of +65 -year-olds were projected to be hospitalized due to cardiovascular issues, $0.8 \%$ due to cardiac issues, and $0.13 \%$ with cardiac failure issues. Shortterm concentrations also made $0.91 \%$ visit the emergency department due to asthma and $0.01 \%$ due to lung malfunction.

- $\mathrm{SO}_{\mathrm{x}}$ long-term health endpoints also made $7.53 \%$ of the population visit the emergency departments for asthma issues as well as $3.86 \%$ with bronchodilator use due to the Incidence of myocardial infarction.

- The analysis identified evidence of a threshold in the relationship between yearly concentrations of emissions and all-cause mortality, morbidity, emergency department visits, and heart attacks. The daily concentration analyses also identified evidence of a threshold between short-term concentrations and all-cause mortality, hospitalization, emergency department visits, and minor morbidities.

This study indicates that the health of residents living near ports is most likely to be affected by different industrial activities. The obvious response is to minimize exposure for those living near ports when emissions from shipping operation activities are at their highest. This study is also one small part of what needs to be a comprehensive overview that incorporates all relevant pathways and exposure scenarios, including occupational exposure, to enable a better understanding of the impacts of primary emissions on public health. A full Health Impact Assessment can identify where and when public health is most likely to be affected, and indicate strategies to reduce negative health impacts. Our preliminary results, indicating that people living near Port of Brisbane face significant health risks, warrant further study.

\section{Short-term and long-term risk assessment of concentrations}

The guidelines from Australia's National Environmental Management Plan (NEMP) and the World Health Organisation (WHO) were implemented to validate the results of the study 
Table 4. Maximum concentrations in the study versus available guidelines.

\begin{tabular}{lcccc}
\hline Pollutants & Averaging time & Concentrations $\left(\mu \mathrm{g} / \mathrm{m}^{3}\right)$ & NEPM & WHO \\
\hline $\mathrm{CO}$ & $10 \mathrm{~min}$ & 1.87 & $\mathrm{n} / \mathrm{a}$ & $100,000\left(\mu \mathrm{g} / \mathrm{m}^{3}\right)$ \\
$\mathrm{CO}$ & $30 \mathrm{~min}$ & 5.83 & $\mathrm{n} / \mathrm{a}$ & $\mathrm{n} / \mathrm{a}$ \\
$\mathrm{CO}$ & $1 \mathrm{hr}$ & 48.6 & $9 \mathrm{ppm}$ & $\mathrm{n} / 000\left(\mu \mathrm{g} / \mathrm{m}^{3}\right)$ \\
$\mathrm{CO}$ & $8 \mathrm{hr}$ & 22.3 & $\mathrm{n} / \mathrm{a}$ & $10,000\left(\mu \mathrm{g} / \mathrm{m}^{3}\right)$ \\
$\mathrm{SO}_{2}$ & $10 \mathrm{~min}$ & 15.7 & $0.2 \mathrm{ppm}$ & $500\left(\mu \mathrm{g} / \mathrm{m}^{3}\right)$ \\
$\mathrm{SO}_{2}$ & $1 \mathrm{hr}$ & 93.8 & $0.08 \mathrm{ppm}$ & $\mathrm{n} / \mathrm{a}$ \\
$\mathrm{SO}_{2}$ & $24 \mathrm{hr}$ & 36.2 & $0.02 \mathrm{ppm}$ & $20\left(\mu \mathrm{g} / \mathrm{m}^{3}\right)$ \\
$\mathrm{SO}_{2}$ & $1 \mathrm{yr}$ & 9.98 & $0.12 \mathrm{ppm}$ & $\mathrm{n} / \mathrm{a}$ \\
$\mathrm{NO}_{2}$ & $1 \mathrm{hr}$ & 25.3 & $0.03 \mathrm{ppm}$ & $200\left(\mu \mathrm{g} / \mathrm{m}^{3}\right)$ \\
$\mathrm{NO}_{2}$ & $1 \mathrm{yr}$ & 10.4 & $50\left(\mu \mathrm{g} / \mathrm{m}^{3}\right)$ & $40\left(\mu \mathrm{g} / \mathrm{m}^{3}\right)$ \\
$\mathrm{PM}_{10}$ & $24 \mathrm{hr}$ & 64.2 & $25\left(\mu \mathrm{g} / \mathrm{m}^{3}\right)$ & $50\left(\mu \mathrm{g} / \mathrm{m}^{3}\right)$ \\
$\mathrm{PM}_{10}$ & $1 \mathrm{yr}$ & 8.3 & $25\left(\mu \mathrm{g} / \mathrm{m}^{3}\right)$ & $20\left(\mu \mathrm{g} / \mathrm{m}^{3}\right)$ \\
$\mathrm{PM}_{2.5}$ & $24 \mathrm{hr}$ & 40.3 & $8\left(\mu \mathrm{g} / \mathrm{m}^{3}\right)$ & $25\left(\mu \mathrm{g} / \mathrm{m}^{3}\right)$ \\
$\mathrm{PM}_{2.5}$ & $1 \mathrm{yr}$ & 8.5 & & $10\left(\mu \mathrm{g} / \mathrm{m}^{3}\right)$ \\
\hline
\end{tabular}

Table 5. Average concentrations in the study vs. available guidelines.

\begin{tabular}{|c|c|c|c|c|}
\hline Pollutant & Averaging time & Concentrations $\left(\mu \mathrm{g} / \mathrm{m}^{3}\right)$ & NEPM & WHO \\
\hline $\mathrm{CO}$ & $10 \mathrm{~min}$ & 0.96 & $\mathrm{n} / \mathrm{a}$ & $100,000\left(\mu \mathrm{g} / \mathrm{m}^{3}\right)$ \\
\hline $\mathrm{CO}$ & $30 \mathrm{~min}$ & 3.25 & $\mathrm{n} / \mathrm{a}$ & $60,000\left(\mu \mathrm{g} / \mathrm{m}^{3}\right)$ \\
\hline $\mathrm{CO}$ & $1 \mathrm{hr}$ & 28.1 & $\mathrm{n} / \mathrm{a}$ & $30,000\left(\mu \mathrm{g} / \mathrm{m}^{3}\right)$ \\
\hline $\mathrm{CO}$ & $8 \mathrm{hr}$ & 17.5 & 9 ppm & $10,000\left(\mu \mathrm{g} / \mathrm{m}^{3}\right)$ \\
\hline $\mathrm{SO}_{2}$ & $10 \min$ & 13.1 & $\mathrm{n} / \mathrm{a}$ & $500\left(\mu \mathrm{g} / \mathrm{m}^{3}\right)$ \\
\hline $\mathrm{SO}_{2}$ & $1 \mathrm{hr}$ & 75.8 & $0.2 \mathrm{ppm}$ & $\mathrm{n} / \mathrm{a}$ \\
\hline $\mathrm{SO}_{2}$ & $24 \mathrm{hr}$ & 19.8 & 0.08 ppm & $20\left(\mu \mathrm{g} / \mathrm{m}^{3}\right)$ \\
\hline $\mathrm{SO}_{2}$ & $1 \mathrm{yr}$ & 7.5 & $0.02 \mathrm{ppm}$ & $\mathrm{n} / \mathrm{a}$ \\
\hline $\mathrm{NO}_{2}$ & $1 \mathrm{hr}$ & 19.63 & $0.12 \mathrm{ppm}$ & $200\left(\mu \mathrm{g} / \mathrm{m}^{3}\right)$ \\
\hline $\mathrm{NO}_{2}$ & $1 \mathrm{yr}$ & 9.84 & $0.03 \mathrm{ppm}$ & $40\left(\mu \mathrm{g} / \mathrm{m}^{3}\right)$ \\
\hline $\mathrm{PM}_{10}$ & $24 \mathrm{hr}$ & 49.7 & $50\left(\mu \mathrm{g} / \mathrm{m}^{3}\right)$ & $50\left(\mu \mathrm{g} / \mathrm{m}^{3}\right)$ \\
\hline $\mathrm{PM}_{10}$ & $1 \mathrm{yr}$ & 6.12 & $25\left(\mu \mathrm{g} / \mathrm{m}^{3}\right)$ & $20\left(\mu \mathrm{g} / \mathrm{m}^{3}\right)$ \\
\hline $\mathrm{PM}_{2.5}$ & $24 \mathrm{hr}$ & 23.74 & $25\left(\mu \mathrm{g} / \mathrm{m}^{3}\right)$ & $25\left(\mu \mathrm{g} / \mathrm{m}^{3}\right)$ \\
\hline $\mathrm{PM}_{2.5}$ & $1 \mathrm{yr}$ & 6.87 & $8\left(\mu \mathrm{g} / \mathrm{m}^{3}\right)$ & $10\left(\mu \mathrm{g} / \mathrm{m}^{3}\right)$ \\
\hline
\end{tabular}

(Tables 4 and 5) (Department of the Environment 2016; WHO regional office for Europe 2000). The maximum and average mean concentrations in the simulated air-shed in this study were less than the safety limit defined for short- and long-term inhalation exposure by NEMP and WHO. Assumptions underlie the offered "worst case" scenarios, one of which is the predicted flow of local-scale air pollution against the meteorological model that the Australian Bureau of Meteorology offers. The predicted flow incorporates the effects of sea breezes and land gradients. Meteorological data for the Port of Brisbane area is scarce, and the associated temporal resolution lacks the level of precision required to analyze a model developed from the data. The applied model, instead, offers an analytical framework that is more accurate and reliable. The Lagrangian Particle Model and Plume Rise Module (Teggi et al. 2018; Xie and Coceal 2018) are used in the simulation of this study to generate the flow at a higher level of accuracy, allowing predictions about the local meteorology that offer advantages over the use of available meteorological data.

\section{Ecological effect risk assessment}

Following the recognition of WHO that protecting the environment benefits human health, this study focused on the ecological effects of $\mathrm{SO}_{\mathrm{x}}$ and $\mathrm{NO}_{\mathrm{x}}$. Some contaminants found in the atmosphere are also believed to cause environmental impacts including PM; however, practical approaches to measuring them have not yet been developed.

Since the publication of "Air Quality Guidelines for Europe" in 1987, emissions from $\mathrm{SO}_{2}$ have fallen in many areas, and it is no longer viewed as the direct danger it once was (WHO regional office for Europe 1987). However, it has a significant effect on plant life with minimal concentrations 
impacting on yield and growth, making plants more susceptible to other types of environmental stress (Bare 2008). The current WHO statistics (2000) suggest the yearly baseline estimate of $30 \mu \mathrm{g} / \mathrm{m}^{3}$ as the standard average concentration; the measurement of $\mathrm{SO}_{2}$ in this study, however, is much lower (Table 5). This is an annual average, however, and it is recommended that in the winter the concentration should be lower as its effect on winter crops is particularly severe. It has also been noted by WHO (1987) that an average daily guideline is not particularly useful as the cumulative effect is a more significant impact on plants. A baseline of $20 \mu \mathrm{g} /$ $\mathrm{m}^{3}$ is then currently recommended (Mcleod and Skeffington 1995). The level of $\mathrm{SO}_{2}$ in this study is lower than the critical range as well (Table 5), and so the attention is mainly on the direct effects of exposure between $1 \mathrm{hr}$ and 1 year.

While there is an established guideline for acceptable levels of $\mathrm{SO}_{2}$, elaborating critical standards for $\mathrm{NH}_{3}, \mathrm{NO}_{2}$, and $\mathrm{NO}$ is not so simple. In most parts of the world, these are the dominant forms of nitrogen deposition according to WHO (2000), but they have several significant effects that are not adequately considered by the acidity or critical loads for nitrogen, which has been based on the physiological and ecological impacts on plants, not on biochemical changes (Camargo and Alonso 2005). Our survey considered that, ecologically, both stimulation and reduction in growth are negative responses to pollutants, and there is a need to comprehend more about prolonged biochemical effects on plants. There is insufficient data to establish the actual impact of critical levels for short-term exposure even with the formulation of a typical scenario. A value of approximately $75 \mu \mathrm{g} / \mathrm{m}^{3}$ for $\mathrm{NO}_{\mathrm{x}}$ as an hour mean has been suggested by WHO regional office for Europe (1987). However, the values in our study are considerably lower (Table 5). Interactive effects involving $\mathrm{NO}_{2}$ and $\mathrm{SO}_{2}$ or ozone have also been reported but a review of recent literature reveals that the smallest efficient levels for combination effects are approximately the same to those for nitrogen (IV) oxide (Adaros 1991; Cape et al. 1991; Caporn et al. 1994; Ito et al. 1984; Van De Geijn et al. 1993). Measuring critical levels for a full year may cover relatively long-term effects. The annual level for $\mathrm{NO}_{\mathrm{x}}$ is 30 $\mu \mathrm{g} / \mathrm{m}^{3}$; moreover, the values in this study are significantly lower (Table 5).

\section{Carcinogenic risk assessment of concentrations}

Receptors are also exposed to exhausts from diesel trains and ships, power generators, and other sources (Zeng et al. 2018). There is already a large evidence to establish environmental standards for diesel exhaust emissions, and governments (mostly in North America and Europe) have established successively tighter emission standards for both diesel and gasoline engines (International Agency for Research on Cancer 2012). For diesel engines, however, standards tend to require a significant decrease in sulphur, changes to engine designs that will lead to more efficient burning, and improvements in exhaust control to reduce emissions (International agency for research on cancer 2012). While these may reduce the quantity of particulates and chemicals, their effect on health is not yet clear. Particulate matter is of great concern specifically because it is carcinogenic and disrupts endocrine activity.

Our study has calculated the risk of exposure through inhalation utilizing an equation of probabilistic risk assessment. For adults, the computed risk of cancer suggests that vulnerability via inhalation is $10 \mathrm{e}-6$, which is the same for the young ones (WHO Regional Office For Europe 2000). This value, called the Incremental Lifetime Cancer Risk (ILCR), considers the probability of any human getting cancer from exposure (to airborne pollutants). The way to validate this value in our study was to calculate the annual average concentration of $\mathrm{PM}_{2.5}$ in the explained air-shed in the Health impact risk assessment section and then to multiply it (for the air-shed and for any individual receptor locations) by $(3.4 \mathrm{e}-5) \mathrm{ug} / \mathrm{m}^{3}$ to calculate the individual ILCR for each person in that air-shed. A final ILCRs below $10 \mathrm{e}-6$ is considered acceptable and in our study, the sequence of calculating the cancer risk was "industrial sites > busy traffic sites $>$ sensitive sites $>$ residential sites. The individual danger through inhalation in our study $(2.34 \mathrm{e}-04)$ is more than the recommended risk, therefore the risk of developing cancer from inhaling particles is not negligible. The potential 
for synergic or additive impact between toxic organic compounds and fine particles can also raise the vulnerability of cancer development through inhalation even though it accounts for a small percentage of the total intake of concentrations. Extensive research is required to improve the understanding of sources of airborne contaminants. Such studies can contribute to the formulation of adequate regulations to improve the standards for air quality in Australian ports.

\section{Conclusion}

This article studied the suitability of health risk frameworks for assessing shipping emissions within Australian ports. The complete application of such a methodology to shipping emissions is unique and holds great potential for future development. Of greatest interest is the continued evaluation of results from ports over an extended period. This study showed that applying the emission inventory results to a detailed dispersion model of Port of Brisbane and completing the associated risk assessment provides a convincing argument for the need to combat the widespread effects of ship emissions.

To the best of our knowledge, this study is the initial comprehensive report addressing the distribution, concentration, sources, and health vulnerability assessments of primary emissions in ports found in Australia. Further research can be conducted in several areas within the same topic. One of them includes an investigation and further analysis of shipping exhaust emissions using finer atmospheric aerosols. Source apportionments and dispersion modeling with an increased amount of samples can be executed to offer extensive knowledge regarding emission distribution and sources. Moreover, more research on characterizing parameters that contribute more crucially to the vulnerabilities estimation must be conducted.

Further study may reduce the uncertainties in current assessments of the effect of exposure to atmospheric emissions and improve the direct efforts to curb exposure as well as addressing the limitations identified in the risk assessment (Mckenzie et al. 2012). Further work may model short- and longer- term exposures and collect relevant data by area, residence, and personal vulnerability, with emphasis on short-term peak emissions. There is also a need to investigate the toxicity level of hydrocarbons like alkanes, and the health impacts they possess when mixed with other pollutants in the atmosphere associated with primary emissions.

\section{Disclosure}

No potential conflict of interest was reported by the authors.

\section{ORCID}

Sanaz Jahangiri (D) http://orcid.org/0000-0001-5139-8213

Natalia Nikolova (D) http://orcid.org/0000-0001-6160-6282

Kiril Tenekedjiev (iD http://orcid.org/0000-0003-3549-0671

\section{References}

Adaros G. 1991. Single and interactive effects of low levels of $\mathrm{O}_{3}, \mathrm{SO}_{2}$ and $\mathrm{NO}_{2}$ on the growth and yield of spring rape. Environ Pollut. 72:269-86.

Amoatey P, Omidvarborna H, Baawain M. 2017. Modeling of particulate matter dispersion from a cement plant: upwind-downwind case study. J Hum Ecol Risk Assess. 24:1181-96.

Atkinson R, Yu D, Armstrong BG, Pattenden S, Wilkinson P, Doherty RM, Heal MR, Anderson HR. 2012. Concentration-response function for Ozone and daily mortality: results from Five Urban and Five Rural U.K. Populations. Environ Health Perspect. 120(10):1411-1417.

Bailey D, Solomon G. 2004. Pollution prevention at ports: clearing the air. Environ Impact Assess Rev. 24:749-77.

Barclay J, Borissova M 2013. Potential problems using aermod to implement current odor regulations for wwtps. International Water Association Conference on Odors and Air Emissions. San Francisco, California, USA.

Bare J. 2008. The tool for the reduction and assessment of chemical and other environmental impacts. J Ind Ecol. 6:49-78.

Bluett, J., N. Gimson, G. Fisher, C. Heydenrych and T. Freeman, J. Godfrey. 2004. Good practice guide for atmospheric dispersion modelling. New Zealand Ministry Environ.

Briggs GA. 1974. Diffusion estimation for small emissions. Oak Ridge (Tennessee): US Atomic Energy Commission.

California Environmental Protection Agency. 2006. Emission Reduction Plan for Ports and Goods Movement in California - Appendix A: Quantification of the Health Impacts and Economic Valuation of Air Pollution from Ports and Goods Movement in CA. Air Resources Board, USA. 
Camargo J, Alonso A. 2005. Ecological and toxicological effects of inorganic nitrogen pollution in aquatic ecosystems: A global assessment. Environ Int. 32:831-49.

Cape JN, Leith ID, Fowler D, Murray MB, Sheppard LJ, Eamus D, Wilson RHF. 1991. Sulfate and ammonium in mist impair the frost hardening of red spruce seedlings. New Phytol. 118:119-26.

Caporn TM, Hand DW, Mansfield TA, Wellburn AR. 1994. Canopy photosynthesis of CO2-enriched lettuce (Lactuca sativa L.). Response to short term changes in CO2, temperature and oxides of nitrogen. New Phytol. 126:45-52.

Carotenuto F, Gualtieri G, Miglietta F, Riccio A, Toscano P, Wohlfahrt G, Gioli B. 2018. Industrial point source $\mathrm{CO}_{2}$ emission strength estimation with aircraft measurements and dispersion modelling. Environ Monit Assess. 190(3): 165.

Clarkson D. 2015. Development of a risk-based methodology to assess the impact of vessel emissions within Australian ports. (UTAS), Australia: Australian Maritime College.

Cofala J, Amann M, Klimont Z, Posch M, Schöpp W, Tarasson L, Jonson JE, Whall C, Stavrakaki A 2007. Final Report: Analysis of Policy Measures to Reduce Ship Emissions in the Context of the Revision of the National Emissions Ceilings Directive.

Collins K. 2009. Health impact assessment: a step toward health in all policies. J Ama. 302:315-17.

Colvile R, Hutchinson E, Mindell J, Warren R. 2001. The transport sector as a source of air pollution. Atmos Environ. 35:1537-65.

Cooper D. 2003. Exhaust emissions from ships at berth. Atmos Environ. 37:3817-30.

Corbett J, Koehler H. 2003. Updated emissions from ocean shipping. J Geophys Res Atmos. 108(D20): 9-1-9-13.

Department of the Environment 2016. National Environment Protection (Ambient Air Quality) Measure. National Environment protection council [accessed 2019 Jan 14]. http://www.nepc.gov.au/nepms/ambient-air-quality

EnHealth 2012. Environmental health risk assessment guidelines for assessing human health risk assessment. enHealth [accessed 2019 Jan 14]. https://www.eh.org.au/ documents/item/916

Eyring V, Isaksen IS, Berntsen T, Collins WJ, Corbett JJ, Endresen O, Stevenson DS. 2010. Transport impacts on atmosphere and climate: shipping. Atmos Environ. 44:4735-71.

Eyring V, Köhler H, Aardenne J, Lauer A. 2005. Emissions from international shipping: 1 . The last 50 years. J Geophys Res Atmos. 110(D17305). doi: 10.1029/2004JD005619.

Goldsworthy L, Goldsworthy B. 2015. Modelling of ship engine exhaust emissions in ports and extensive coastal waters based on terrestrial AIS data - An Australian case study. Environ Modell Software. 63:45-60.

Goldsworthy L, Renilson M. 2013. Ship engine exhaust emission estimates for Port of Brisbane. Air Qual Clim Change. 7:26-36.

Holmes NSALM. 2006. The dispersion of particles: an overview of different dispersion models available. Atmos Environ. 40:5902-28.

IMO. 2014. MARPOL Annex VI. International Maritime Organization [accessed 2019 Jan 14]. https://www.iomshi pregistry.com/media/1504/sd2014-0223-merchantshippingmarpolannexvi-preventionofairpollution-order2014.pdf

International agency for research on cancer. 2012. Diesel engine exhaust carcinogenic. Lyon, France: World Health Organisation.

Isakov V, Sax T, Venkatram A, Pankratz D, Heumann J, Fitz D. 2004. Near-field dispersion modeling for regulatory applications. J Air Waste Manage Assoc. 54:473-82.

Ito O, Okano K, Totsuka T. 1984. Effects of $\mathrm{NO}_{2}$ and $\mathrm{O}_{3}$ alone or in combination on kidney bean plants. II. Amino acid pool size and composition. Tokyo, Japan: National Institute of Environmental Studies.

Jahangiri S, Nikolova N, Tenekedjiev K. 2018a. Application of a developed dispersion model to port of Brisbane. Am J Environ Sci. 14:156-69.

Jahangiri S, Nikolova N, Tenekedjiev K. 2018b. An improved emission inventory method for estimating engine exhaust emissions from ships. J Sustainable Environ Res. 28: In Press, Accepted Manuscript doi: 10.1016/j.serj.2018.08.005.

Jalkanen JP, Brink A, Kalli J, Pettersson H, Kukkonen J, Stipa T. 2009. A modelling system for the exhaust emissions of marine traffic and its application in the Baltic Sea area. Atmos Chem Phys. 9:9209-23.

Khaniabadi Y, Sicard P, Taiwo A, Marco A, Esmaeili S, Rashidi R. 2018. Modeling of particulate matter dispersion from a cement plant: upwind-downwind case study. J Environ Chem Eng. 6:3104-10.

Lucialli P, Ugolini P, Pollini E. 2007. Harbour of Ravenna: the contribution of harbour traffic to air quality. Atmos Environ. 41:6421-31.

Mckenzie L, Witter R, Newman L, Adgate J. 2012. Human health risk assessment of air emissions from development of unconventional natural gas resources. Sci Total Environ. 424:79-87.

Mcleod AR, Skeffington RA. 1995. The Liphook forest fumigation project - an overview. Plant, Cell and Environ. 18:327-36.

NOAA. 2017. GSHH-a global self-consistent, hierarchical, high-resolution geography database. NOAA. National Centers for Environmental Information.

NSW EPA. 2005. Approved methods for the modelling and assessment of air pollutants in New South Wales. Sydney, Australia: NSW EPA.

Scire JD 2000. A user's guide for the CALPUFF dispersion model. Standards Australia. 2009. Australia/New Zealand Standard. Risk management. Principles and guidelines AS/NZS ISO 31000:2009.

Teggi S, Costanzini S, Ghermandi G, Malagoli C, Vinceti M. 2018. A GIS-based atmospheric dispersion model for pollutants emitted by complex source areas. Sci Total Environ. 610-611:175-90.

USGS. 2017. Shuttle radar topography mission (SRTM) 1 Arc-second global. Reston, VA: USGS.

Van De Geijn SC, Goudriaan J, van der Eerden LJ, Rozema J. 1993. Problems and approaches to integrating the concurrent impacts of elevated $\mathrm{CO}_{2}$, temperature, $\mathrm{UVb}$ radiation and $\mathrm{O}_{3}$ on crop production. In: Buxton IDR et al., editors. International Crop 
Science. Madison, WI: Crop Science Society of America. p. 333338.

WHO regional office for Europe. 1987. Air quality guidelines for Europe. Copenhagen, Denmark: WHO Regional Publications. WHO regional office for Europe. 2000. Air quality guidelines for Europe. Copenhagen, Denmark: WHO Regional Publications. Winebrake J, Corbett J, Green E, Lauer A, Eyring V. 2009. Mitigating the health impacts of pollution from oceangoing shipping: an assessment of low-sulphur fuel mandates. Environ Sci Technol. 43:4776-82.
Xie T, Coceal O. 2018. Evaluation of fast atmospheric dispersion models in a regular street network. J Environ Fluid Mech. 18:1007-44.

Zeng Q, Jeppesen E, Gu X, Mao Z, Chen H. 2018. Distribution, fate and risk assessment of PAHs in water and sediments from an aquaculture- and shipping-impacted subtropical lake, China. Chemosphere 201:612-620.

Zhang J, Hodgson J, Erkut E. 2000. Using GIS to assess the risks of hazardous materials transport in networks. Eur J Oper Res. 121:316-29. 